Article

\title{
Synthesis of Mesoporous MWCNT/HKUST-1 Composite for Wastewater Treatment
}

\author{
Rasidi Sule *(1) and Ajay K. Mishra * \\ Nanotechnology and Water Sustainability Research Unit, College of Science, Engineering \& Technology, \\ University of South Africa, Florida Science Campus, Johannesburg 1709, South Africa \\ * Correspondence: suler@unisa.ac.za (R.S.); mishrak@unisa.ac.za (A.K.M.); Tel.: +27-116-709-702 (A.K.M.)
}

Received: 26 August 2019; Accepted: 20 September 2019; Published: 18 October 2019

\begin{abstract}
Metal-organic frameworks (MOFs) (Hong Kong University of Science and Technology (HKUST)-1) have been widely studied using the hydrothermal method. Recently, efforts have also been geared toward the incorporation of multiwalled carbon nanotubes (MWCNTs) into the HKUST-1 MOF to advance its applications for gas storage as well as pollutant removal in wastewater. However, a significant reduction in the MWCNT/HKUST-1 composite surface area has limited its applications. We therefore synthesized HKUST-1 and HKUST-1 impregnated with acid-treated multiwalled carbon nanotubes (FMWCNTs). A large surface area of $1131.2 \mathrm{~m}^{2} \mathrm{~g}^{-1}$ was obtained after acid treatment of the as-received MWCNTs. HKUST- 1 was found to have an average particle diameter of 6.5 to $8 \mu \mathrm{m}$ with a BET surface area of $1176.66 \mathrm{~m}^{2} \mathrm{~g}^{-1}$. The FMWCNT/HKUST-1 composites had a BET surface area of $1108.85 \mathrm{~m}^{2} / \mathrm{g}$. The addition of FMWCNTs was found to increase the parent MOF pore volume from 0.76 to $1.93 \mathrm{~cm}^{3} \mathrm{~g}^{-1}$. A BJH desorption cumulative pore size of $6.97 \mathrm{~nm}$ was obtained in a composite sample. The maximum adsorption capacity of the composites was found to be greater than $100 \mathrm{mg} / \mathrm{g}$ at $298 \mathrm{~K}$. The results obtained indicate that FMWCNT/HKUST-1 nanocomposites are a potential adsorbent for methylene blue (MB) removal in dye synthetic water.
\end{abstract}

Keywords: HKUST-1 MOF; carbon nanotubes; methylene blue; characterization; adsorption

\section{Introduction}

Metal-organic frameworks (MOFs) have been found to be more versatile than any other class of porous material in applications. This is due to their unique features, such as large surface areas with tunable porosities, open metal sites, and the ability to incorporate specific functionalities and active species without altering the frame topology [1-3]. These properties have made MOFs an outstanding material for gas storage, the capture of $\mathrm{CO}_{2}$, and wastewater treatment $[4,5]$.

Among these MOFs, the Hong Kong University of Science and Technology (HKUST)-1 MOF has been widely studied for energy-related applications [6]. Recently, the HKUST-1 MOF has also received significant attention in wastewater treatment due to its distinct properties [7]. However, MOF instability with water and poor chemical and thermal stabilities are major challenges in water purification [8,9]. DeCoste et al. [10] reported on the effect of water adsorption on the structure of metal-organic frameworks. It was found that $\mathrm{Cu}_{3}(\mathrm{BTC})_{2}$ suffers surface area loss, crystallinity variation, and crystal surface damage. On the other hand, Al-Janabi et al. [11] showed that the stretch of the $\mathrm{Cu}_{2} \mathrm{C}_{4} \mathrm{O}_{8}$ cage was as a result of absorbed water molecules near $\mathrm{Cu}$ sites. To improve the limiting properties of HKUST-1 MOFs, graphene nanosheets, graphite, and carbon nanotubes have been functionalized and incorporated into the MOF [12-15].

Previous studies have shown that MOFs can be synthesized through solvothermal/hydrothermal $[14,16]$, microwave-assisted [17-19], sonochemical [20,21], electrochemical [22-24], mechanochemical [25,26], ionothermal [27,28], dry gel conversion [29,30], and microfluidic synthesis methods [31,32]. However, 
the solvothermal technique is the most commonly used method in the synthesis of HKUST-1. The reason is that the reaction does not require sophisticated equipment, and it is an economically viable process on an industrial scale [33]. In addition, the route is good for growing quality crystals with high levels of crystallinity, phase purity, and large surface areas [33].

Although remarkable work has been done on the synthesis of HKUST-1 and carbonbased/HKUST-1 composites, very few studies on HKUST-1 and MWCNT/HKUST-1 composites have really resulted in quality crystals with large surface areas. Judging from a literature survey on HKUST-1 and MWCNT/HKUST-1 composites, some studies have reported extremely large surface areas, while others have reported very small values using a solvothermal/hydrothermal synthesis technique. Recently, Chem et al. [34] also attempted to improve the yield and surface area of HKUST-1 using an atmospheric pressure method. However, the typical octahedral crystal structure of HKUST-1 could not be observed. Table 1 summarizes selected results on the BET surface area and pore volume of HKUST-1, SWCNT/HKUST-1, and the MWCNT/HKUST-1 composite using the hydrothermal method.

Table 1. Textural properties of $\mathrm{Cu}-\mathrm{BTC}$ metal-organic framework (MOF) (Hong Kong University of Science and Technology (HKUST-1)) synthesized using the hydrothermal method.

\begin{tabular}{|c|c|c|c|}
\hline Sample & $\mathrm{S}_{\mathrm{BET}}\left(\mathrm{m}^{2} \mathrm{~g}^{-1}\right)$ & $V_{P}\left(\mathrm{~cm}^{3} \mathrm{~g}^{-1}\right)$ & Ref. \\
\hline HKUST-1 & 1009.00 & 0.064 & Lin et al. [35] \\
\hline HKUST-1 & 841.00 & 0.433 & Zu et al. [9] \\
\hline $\mathrm{Cu}-\mathrm{BTC} \mathrm{MOF}$ & 856.00 & 0.031 & Jabbari et al. [14] \\
\hline HKUST-1 & 1345.90 & $\mathrm{~N} / \mathrm{A}$ & Loera-Serna et al. [36] \\
\hline MOF-199 & 1370.00 & 0.57 & Selehi and Anbia [13] \\
\hline CNT/Cu-BTC MOF & 123.25 & 0.081 & Jabbari et al. [14] \\
\hline CNT/MOF-199 & 1280 & 0.49 & Selehi and Anbia [13] \\
\hline HKUST-1 & 1615 & 0.69 & Chen et al. [34] \\
\hline
\end{tabular}

It can be noted that only a few reports on MWCNT/HKUST-1 have produced surface areas and pore volumes higher virgin HKUST-1. This could be one of the reasons graphene and SWCNT are commonly used for HKUST-1 carbon-based composites. Thus, more studies are needed on the synthesis and characterization of HKUST-1 and the MWCNT/HKUST-1 composite. In this paper, we investigated the influence of the synthesis process on the crystal structure, surface area, pore volume, and pore size of the MWCNT/HKUST-1 composite, with potential applications in wastewater.

\section{Experimental Procedures}

\subsection{Materials and Methods}

A commercial copper (II) nitrate hemi-penta-hydrate (ACS reagent, 98\% (Sigma-Aldrich)), benzene-1,3,5-tricarboxylic acid (BTC) with 96\% purity (Sigma-Aldrich), and a multiwalled carbon nanotube (MWCNT) (purity $\geq 98 \%$ ) carbon basis with an outer diameter of $10 \pm 1 \mathrm{~nm}$, an inner diameter of $4.5 \pm 0.5 \mathrm{~nm}$, and a length of 3-6 $\mu \mathrm{m}$ were used for this study. The carbon nanotubes were supplied by Sigma-Aldrich. Nitric acid (55\%), ethanol (99.9\%), and deionized water were used for the experiments.

\subsection{Functionalization of MWCNTs and Characterization}

The as-received MWCNTs were functionalized by treatment with acid. Due to the diameter of the as-received MWCNTs, it was decided that a mild acid treatment should be used in order to not damage the carbon nanotubes. Approximately $2 \mathrm{~g}$ of MWCNTs were treated with $130 \mathrm{~mL}$ of $55 \% \mathrm{HNO}_{3}$ in a round-bottom flask of $500 \mathrm{~mL}$. The solution was oxidized under reflux at $80^{\circ} \mathrm{C}$ for $6 \mathrm{~h}$. The solution was washed severally with deionized water and then with ethanol to prevent the agglomeration of carbon nanotubes during drying. The water from the functionalized MWCNTs had a $\mathrm{pH}$ of approximately 7. The slurry of the functionalized MWCNTs was dried at $80^{\circ} \mathrm{C}$ for $24 \mathrm{~h}$. The morphology of the as-received MWCNTs and functionalized MWCNTs was examined through high-resolution scanning 
electron microscopy (HRSEM Joel 7800F) equipped with EDS analysis. Powder X-ray diffraction (RXD) was used to identify the phases present. The presence of functional groups on the carbon nanotubes was examined through Fourier-transform infrared spectroscopy (FTIR). This technique helped in accessing the carboxylic functional group on the treated MWCNT surfaces. Since carbon nanotubes exhibit strong absorbance due to their black characteristics, a very small number of CNTs were blended with $\mathrm{KBr}$ powder to form a pellet that was used for FTIR analysis.

\subsection{Synthesis and Characterization of MOF and CNT/MOF Nanocomposites}

Porous HKUST-1 MOFs were prepared using the solvothermal method described by Lin et al. [35] and Schlichte et al. [37] (but slightly modified). In this study, $1.018 \mathrm{~g}$ of copper (II) nitrate hemi-penta-hydrate was dissolved in $10 \mathrm{~mL}$ of deionized water, and $0.508 \mathrm{~g}$ of benzene-1,3,5-tricarboxylic acid (BTC) was dissolved in $10 \mathrm{~mL}$ of ethanol. The two solutions were mixed together and stirred thoroughly for $15 \mathrm{~min}$ until the $\mathrm{H}_{3} \mathrm{BTC}$ was completely dissolved. The slurry was transferred into a 240-mL Teflon-liner stainless steel autoclave: $2 \mathrm{~mL}$ of water was used to rinse the mixture of $\mathrm{Cu}$-salt and $\mathrm{H}_{3} \mathrm{BTC}$ inside the autoclave, and an additional $2 \mathrm{~mL}$ of ethanol was added. The autoclave was placed in an oven, and the temperature was kept at $120^{\circ} \mathrm{C}$ for $24 \mathrm{~h}$. Then, the autoclave was cooled down, and the blue crystals were extracted and washed with deionized water and ethanol to remove the unreacted species. The slurry was dried in an oven for $15 \mathrm{~h}$ to obtain the HKUST-1 MOF sample.

In order to prepare the HKUST-1/MWCNT composite material, $0.5 \mathrm{~g}$ of functionalized MWCNTs were ultrasonicated in $32 \mathrm{~mL}$ of ethanol and vigorously stirred using a magnetic stirrer. Then, $16 \mathrm{~mL}$ of water was added ultrasonicated and stirred. The slurry was further ultrasonicated for $17 \mathrm{~min}$ and stirred for $3 \mathrm{~min}$. The $\mathrm{Cu}\left(\mathrm{NO}_{3}\right)_{2} \cdot 2 \cdot 5 \mathrm{H}_{2} \mathrm{O}$ and $\mathrm{H}_{3} \mathrm{BTC}$ were prepared separately in $10 \mathrm{~mL}$ of water and $10 \mathrm{~mL}$ of ethanol, respectively. The $\mathrm{Cu}$-salt and $\mathrm{H}_{3} \mathrm{BTC}$ ligand was mixed as described above and then mixed with the FMWCNT slurry and stirred. The solution was then ultrasonicated for $10 \mathrm{~min}$ and stirred. The slurry was poured inside the autoclave and put in an oven, and the temperature was set at $120^{\circ} \mathrm{C}$ for $24 \mathrm{~h}$. The resulting material was washed with deionized water and ethanol to remove the unreacted species. The slurry was dried in an oven to obtain the MWCNT/HKUST-1 MOF hybrid composites.

The synthesized MOF and MWCNT/MOF composite samples were characterized with SEM and XRD. The BET surface area was measured using a Micromeritics TriStar II apparatus. Prior to the measurement, the samples were degassed in an ultrahigh purity nitrogen at $90^{\circ} \mathrm{C}$ for $1 \mathrm{~h}$ and then for $5 \mathrm{~h}$ at $200^{\circ} \mathrm{C}$. Thermogravimetric analysis (TGA) of the samples was carried out using PerkinElmer (Pyris 1TGA) scanning from 35 to $900{ }^{\circ} \mathrm{C}$ with a heating rate of $10^{\circ} \mathrm{C} / \mathrm{min}$ under air/nitrogen conditions.

\subsection{Adsorption Experiment}

The adsorption experiment was carried out on methylene blue (MB), a commonly used organic pollutant in industry [12]. A stock solution of methylene blue $(1000 \mathrm{mg} / \mathrm{L})$ was prepared by dissolving $1 \mathrm{~g}$ of methylene blue in $1 \mathrm{~L}$ of distilled water. The solution $\mathrm{pH}$ was adjusted with $0.1 \mathrm{M} \mathrm{HCl}$. An adsorbent dosage of $0.015 \mathrm{~g}$ was treated with $25 \mathrm{~mL}$ of $20 \mathrm{ppm}$ of MB solution and placed inside a thermostatic bath shaker for $24 \mathrm{~h}$. After the experiments, the amount of MB adsorbed was monitored through UV-VIS spectroscopy.

\section{Results and Discussion}

\subsection{Microstructure and Grain Size Evolution}

Figure 1A shows an SEM image of as-received MWCNT powder, while Figure 1B shows an SEM micrograph of the functionalized MWCNTs (FMWCNTs) used to synthesis the MOF-CNT composites in this work. 


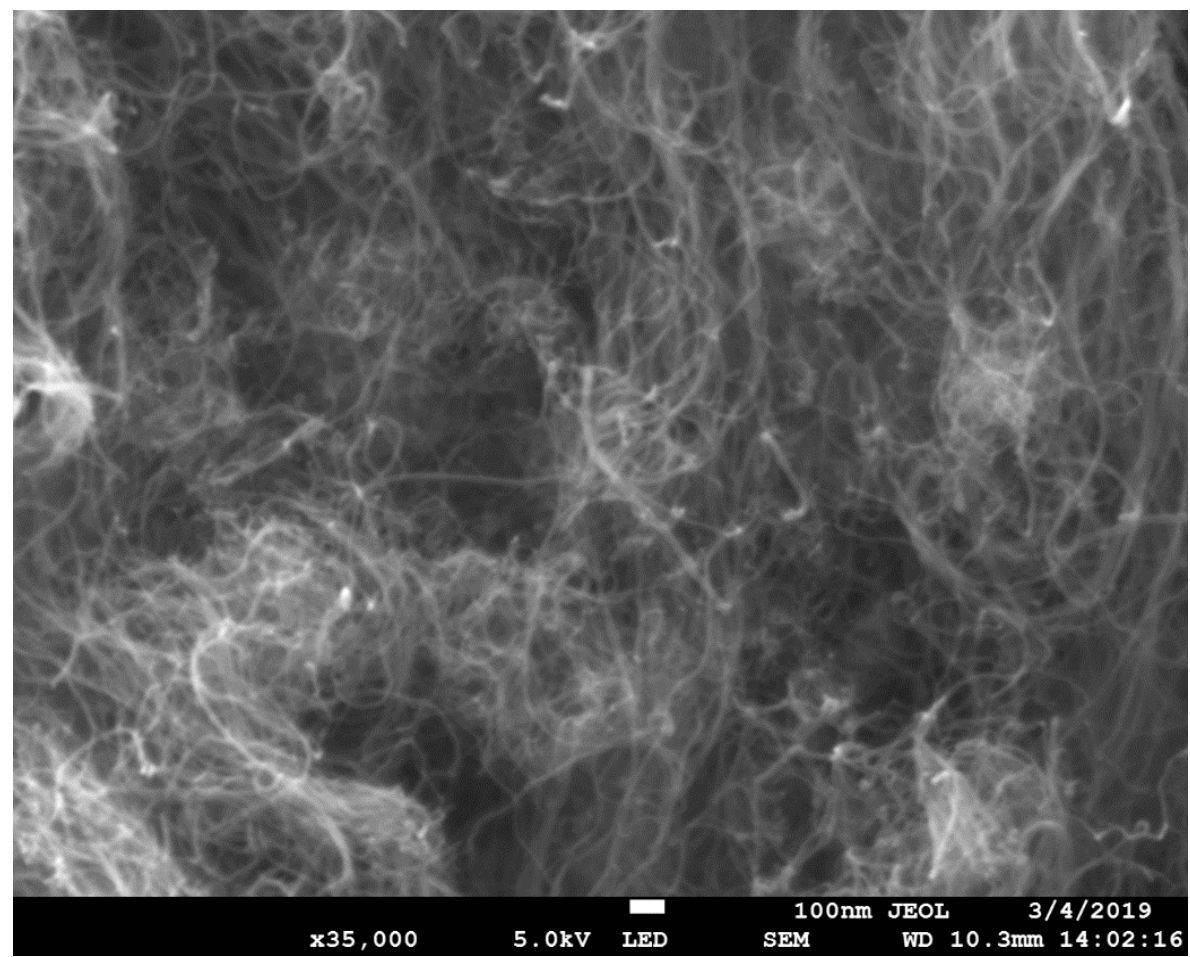

(A)

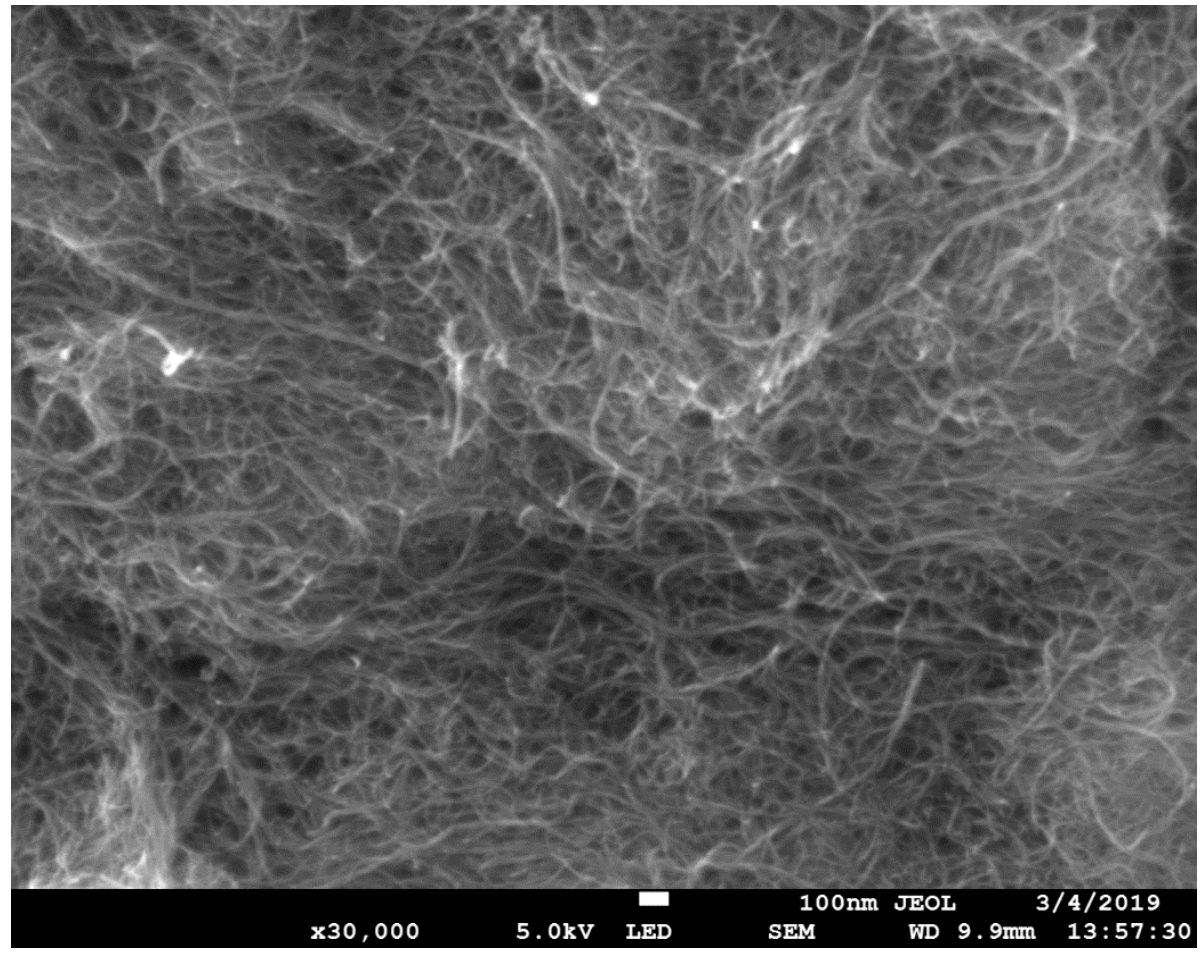

(B)

Figure 1. (A) As-received multiwalled carbon nanotubes (MWCNTs); (B) mill $\mathrm{HNO}_{3}$-functionalized MWCNTs (FMWCNTs).

The high-magnification SEM image of the as-received MWCNTs reveals that they were in bundle form. It can be observed that the acid-treated MWCNTs did not show structural damage, which could have been due to the mild conditions of the $\mathrm{HNO}_{3}$ used. The SEM images reveal a uniform diameter 
distribution and high purity for both the as-received MWCNTs and the functionalized MWCNTs. Figure 2 shows an SEM micrograph/EDS of the as-synthesized HKUST-1 MOF.

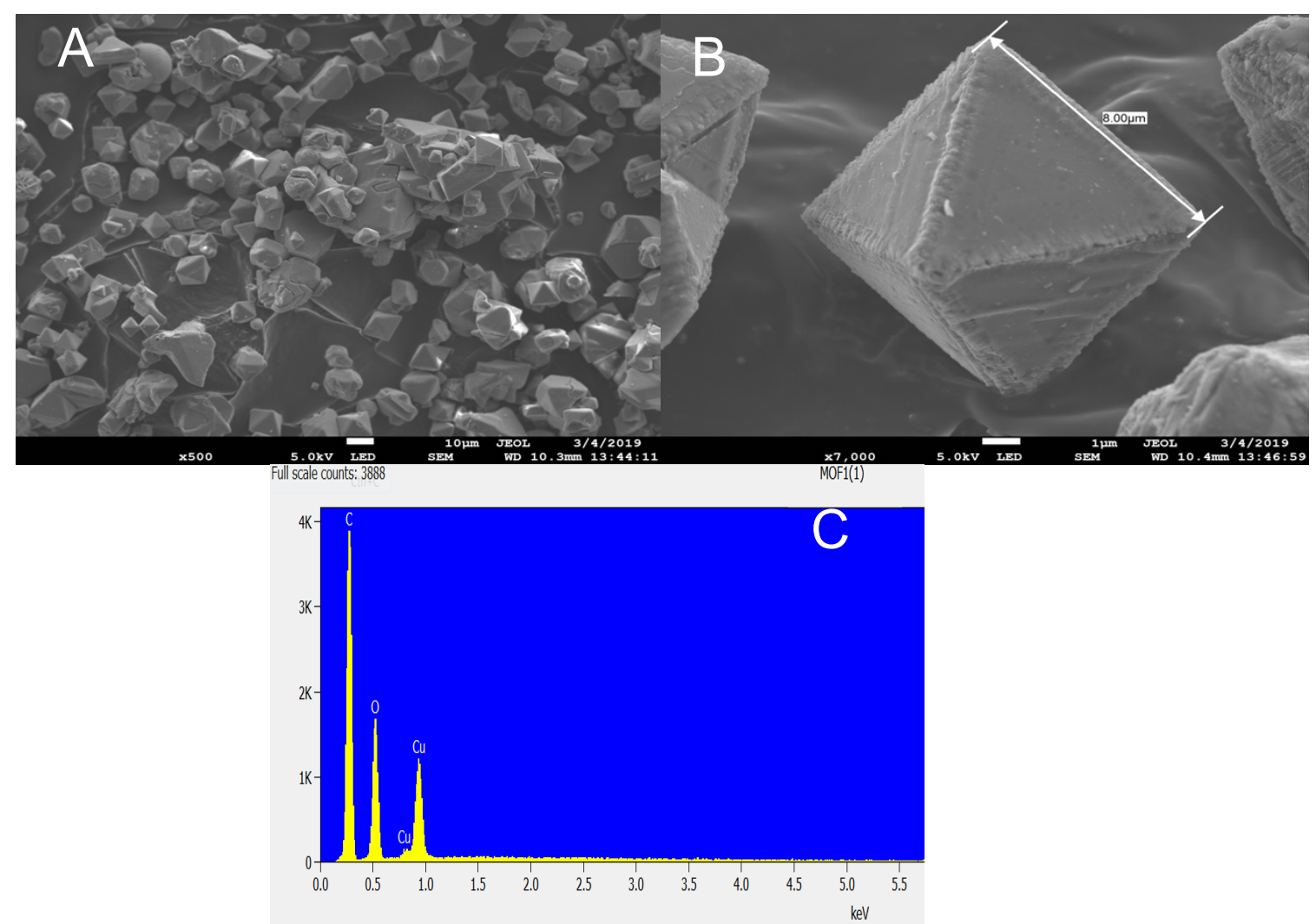

Figure 2. (A) SEM micrograph of HKUST-1 showing the particle shapes; (B) high-resolution SEM micrograph of the HKUST-1 MOF; (C) EDS analysis of the HKUST-1 MOF, showing the elemental composition.

The high-magnification SEM image reveals that the HKUST-1 produced had a well-defined octahedral crystal with average diameter ranges from 6.5 to $8 \mu \mathrm{m}$ with a smooth surface. It can be observed that the method used to produce the HKUST-1 MOF in this work yielded a high-purity product with a cubic shape. This could have served as a basis for the excellent textural properties obtained. The EDS elemental composition revealed only $\mathrm{C}, \mathrm{Cu}$, and $\mathrm{O}$. Previous studies have shown that HKUST-1 synthesized at low temperatures usually results in crystals with a cubic shape and sharp edges [13,35,38]. Wang et al. [39] reported a needle-like structure for $\mathrm{Cu}-\mathrm{BTC}$ prepared by refluxing $\mathrm{DMF} /$ water or ethanol/water solvents under atmospheric conditions. The crystallinity of Cu-BTC synthesized at atmospheric conditions was found to be much lower than that of a hydrothermal reaction. However, $\mathrm{Cu}-\mathrm{BTC}$ synthesized at $150{ }^{\circ} \mathrm{C}$ and agitated for $5 \mathrm{~h}$ in a hydrothermal reaction revealed spherical crystals as well as irregularly shaped particles together with some spherulitic impurity. Figure 3 shows an SEM image of the FMWCNT/HKUST-1 sample. The typical crystals of HKUST-1 were observed on the micrograph. This shows that the carbon nanotube did not prevent or damage the formation of HKUST-1 MOF crystals [9]. The energy dispersive spectroscopy (EDS) of FMWCNT/HKUST-1 composite revealed the presence of carbon, copper and oxygen. 

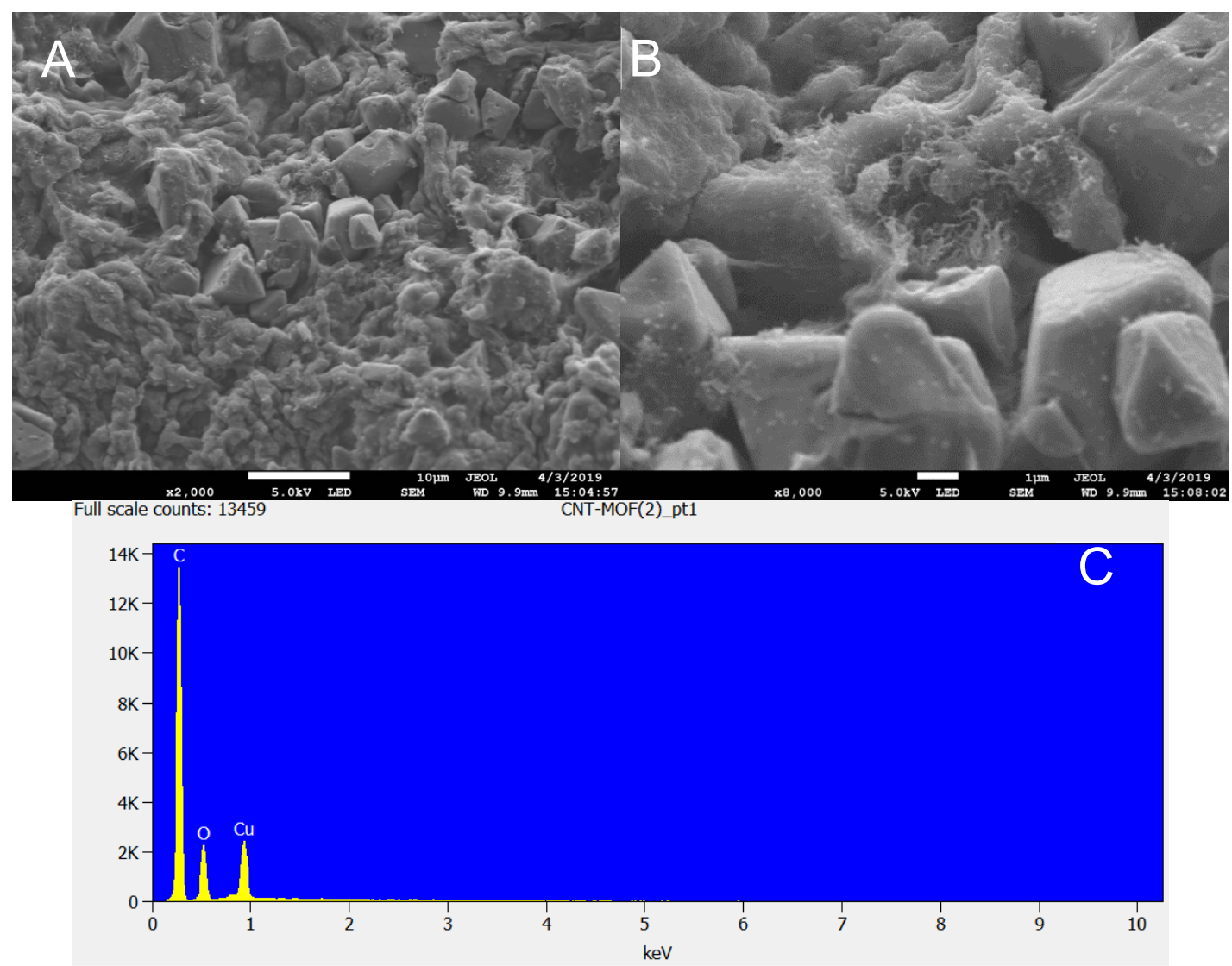

Figure 3. (A) SEM image of FMWCNT/HKUST-1 composite, (B) High resolution image of FMWCNT/HKUST-1 composite, (C) EDS image of FMWCNT/HKUST-1 composite.

\subsection{X-Ray Diffraction and FTIR Analysis}

An X-ray diffraction pattern was used to identify the phase present in both the as-received and acid-treated MWCNTs. Figure 4 shows stack XRD traces of the as-received as well as the functionalized MWCNT samples.

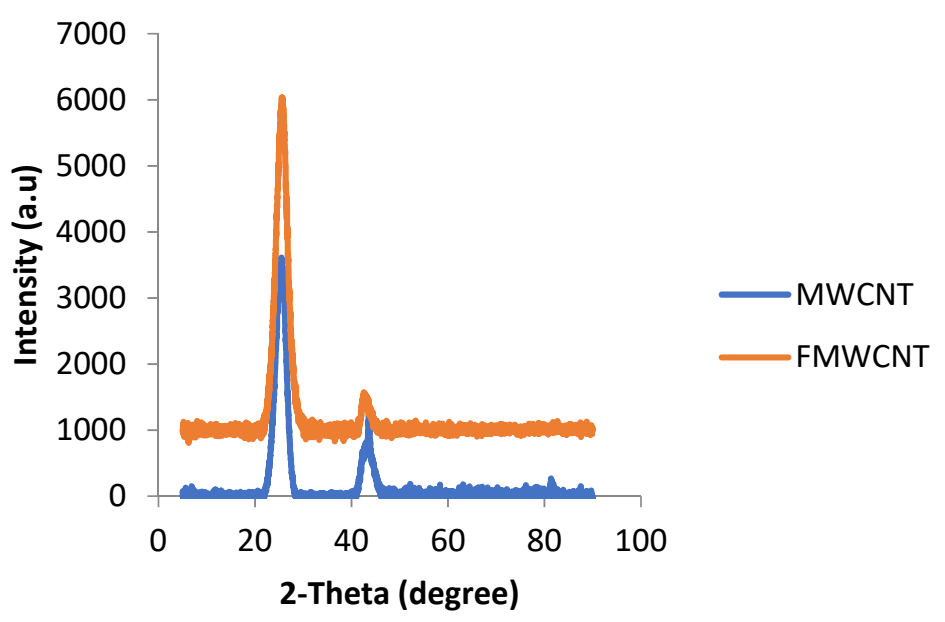

Figure 4. XRD trace of as-received MWCNTs and acid-treated MWCNTs (FMWCNTs).

Similar phases were observed in the samples, and a prominent peak of carbon nanotubes was obtained at a $2 \theta$ angle of $26.8^{\circ}$. However, it can be noted that the functionalized MWCNT peak at $26.8^{\circ}$ increased in intensity compared to the as-received sample. This could have been because of the fact 
that carbon nanotubes loosen after treatment with acid to form well-ordered MWCNTs, and this is evident in Figure 1A,B [40]. The X-ray diffraction pattern of the as-synthesized MOF and that of the composite sample are shown in Figure 5.

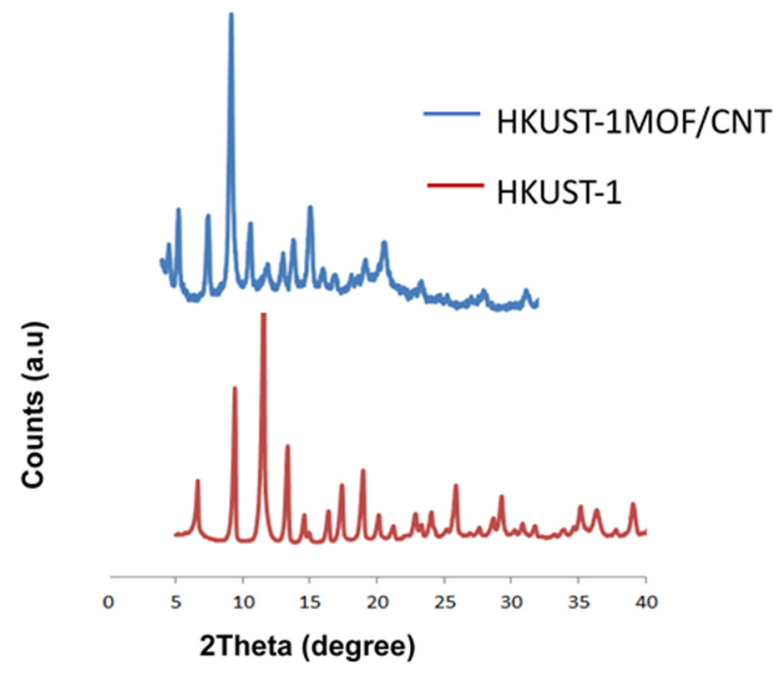

Figure 5. Stack XRD pattern of HKUST-1 and the FMWCNT/HKUST-1 composite.

A typical diffraction pattern of $\mathrm{Cu}_{3}(\mathrm{BTC})_{2}\left(\mathrm{H}_{2} \mathrm{O}\right)_{3} \cdot \mathrm{xH}_{2} \mathrm{O}$ was observed in the virgin MOF samples. The $2 \theta$ position of the prominent peaks of HKUST-1 synthesized in this work matched the high-purity HKUST-1 XRD pattern reported in the literature $[35,37,38]$. The EDS result corroborated the XRD pattern, which gives an indication that no other phase was present in the HKUST-1 sample. On the other hand, HKUST-1 containing functionalized MWCNT samples revealed distinct peaks of HKUST-1. This shows that the carbon nanotube did not prevent the formation of HKUST-1 crystals, but a peak shift was observed in the sample. In addition, the prominent peak of functionalized MWCNTs (observed in Figure 4 at $2 \theta 26.8^{\circ}$ ) was greatly reduced in the composite XRD pattern. This could have been because of the relatively low intensity of MWCNTs compared to HKUST-1 MOFs [9]. This observation is reasonably consistent with a report on MOF-5/MWCNT composites [41]. The FTIR spectrums of the as-received MWCNTs, FMWCNTs, HKUST-1 MOFs, and FMWCNT/HKUST-1 composites synthesized in this study are shown in Figure 6.

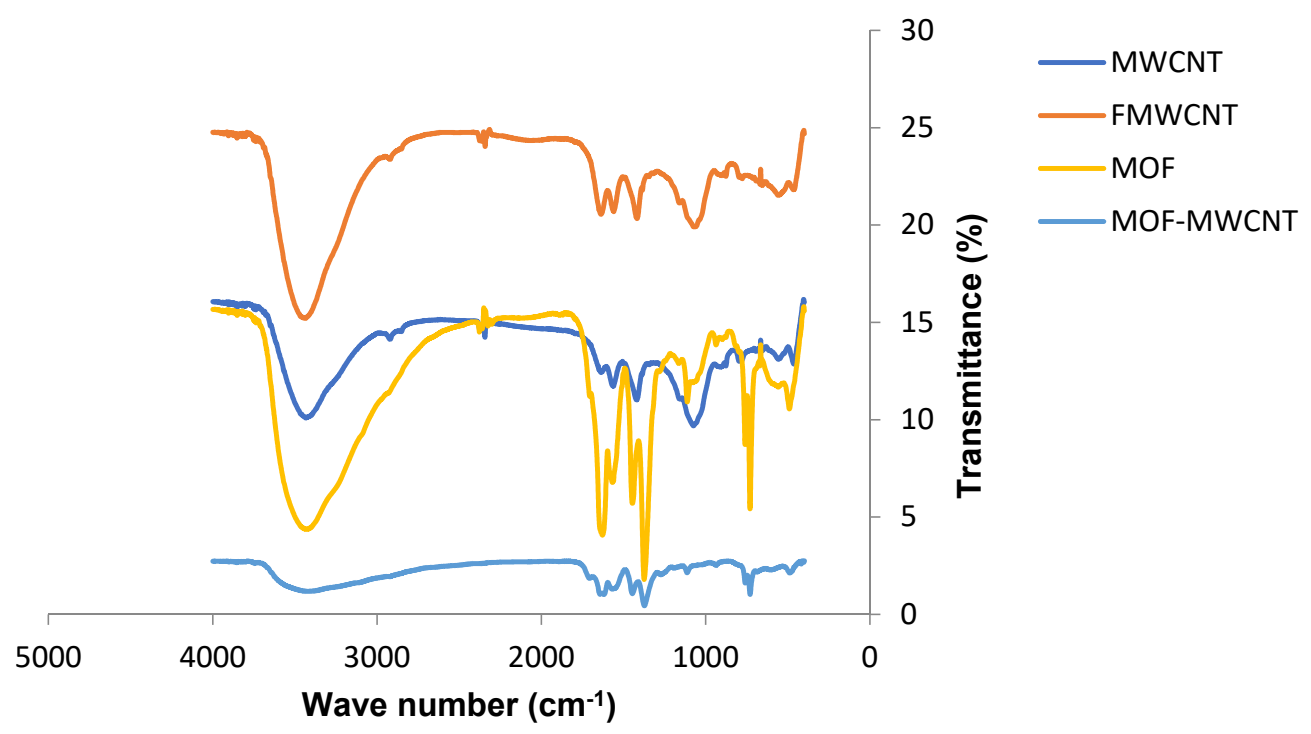

Figure 6. FTIR spectra of the as-received MWCNTs, acid-treated MWCNTs, HKUST-1 MOFs, and FMWCNT/HKUST-1 composites. 
The FTIR spectra of the HKUST-1 revealed a broad peak at $3458 \mathrm{~cm}^{-1}$ that corresponded to an $\mathrm{O}-\mathrm{H}$ stretch of the hydroxyl group in the structure. The peaks at 1628 and $1377 \mathrm{~cm}^{-1}$ corresponded to a -COO group that originated from symmetric stretching of the BTC carboxylate [36]. The band at $1110 \mathrm{~cm}^{-1}$ was attributed to an $\mathrm{C}-\mathrm{O}-\mathrm{Cu}$ vibration in the MOF structure [14]. The FMWCNT/HKUST-1 composite spectra were similar to those of the HKUST-1 MOFs.

\section{3. $\mathrm{N}_{2}$ Adsorption/Desorption Isotherms}

The nitrogen adsorption and desorption isotherms of the samples are shown in Figure 7a. The isotherm for the as-received MWCNTs, HKUST-1, and FMWCNT/HKUST-1 composites exhibited hysteresis loops, which are associated with mesopores. It can be observed that the hysteresis loops of the MWCNTs were of type H1, while those of HKUST-1 and the FMWCNT/HKUST-1 composites belonged to type H4. According to Sing [42], the characteristic features of the type H4 hysteresis loop is its narrow slit-like shape over a range of high relative pressure $(P / P o)$. A small hysteresis loop was observed at a high relative pressure in the HKUST-1 sample. It is worth noting that the addition of functionalized MWCNTs resulted in a broader hysteresis loop of virgin HKUST-1 MOFs. Table 2 summarizes the textural properties of as-received MWCNT, functionalized MWCNT, HKUST-1 and FMWCNT/HKUST-1 composite calculated from the isotherms. The HKUST-1 MOF had the highest surface area, $1177 \mathrm{~m}^{2} / \mathrm{g}$.

Table 2. Textural properties of HKUST-1 and the composites synthesized in this study using the hydrothermal method.

\begin{tabular}{cccc}
\hline Sample & $\begin{array}{c}\text { BET Surface } \\
\left.\text { Area } \mathbf{( m}^{\mathbf{2}} \mathbf{g}^{-\mathbf{1}}\right)\end{array}$ & $\begin{array}{c}\text { BJH Desorption Average } \\
\text { Pore Diameter } \mathbf{( n m )}\end{array}$ & $\begin{array}{c}\text { BJH Desorption Cumulative } \\
\text { Pore Volume } \mathbf{~}^{\mathbf{3}} \mathbf{g}^{\mathbf{- 1}} \mathbf{)}\end{array}$ \\
\hline As-received MWCNTs & 277.18 & 12.88 & 0.89 \\
FMWCNTs & 1131.20 & 3.43 & 0.09 \\
HKUST-1 & 1176.66 & 2.57 & 0.76 \\
FMWCNT/HKUST-1 & 1108.85 & 6.97 & 1.93 \\
\hline
\end{tabular}

However, the value of HKUST-1 produced in this study is small compared to the $1615 \mathrm{~m}^{2} / \mathrm{g}$ reported by Chen et al. [34]. This could have been because of the insufficient removal of solvent [9]. It was observed that the MWCNT/HKUST-1 composites showed a slight reduction in surface area relative to the virgin sample. However, the pore size and pore volume were higher than those of the HKUST-1 sample. This could have possibly been due to the MWCNTs, which helped in the removal of unreactive $\mathrm{Cu}$ species that blocked the pores. Yang et al. [43] found that the addition of MWCNTs helped to enhance both the pore size and pore volume of MOF- 5 by removing the unreacted species during pore activation. It is important to note that despite the incorporation of $0.5 \mathrm{~g}$ of functionalized MWCNTs during synthesis, the surface area of FMWCNT/HKUST-1 was relatively close to that of the virgin HKUST-1 sample. The results of the average pore size of HKUST-1 and/FMWCNT/ HKUST-1 suggested that the samples synthesized in this work were mesoporous. Figure $7 \mathrm{~b}, \mathrm{c}$ shows the pore size distribution (PSD) of HKUST-1 and FMWCNT/HKUST-1 calculated using the Barrett-Joyner-Halenda (BJH) method. 

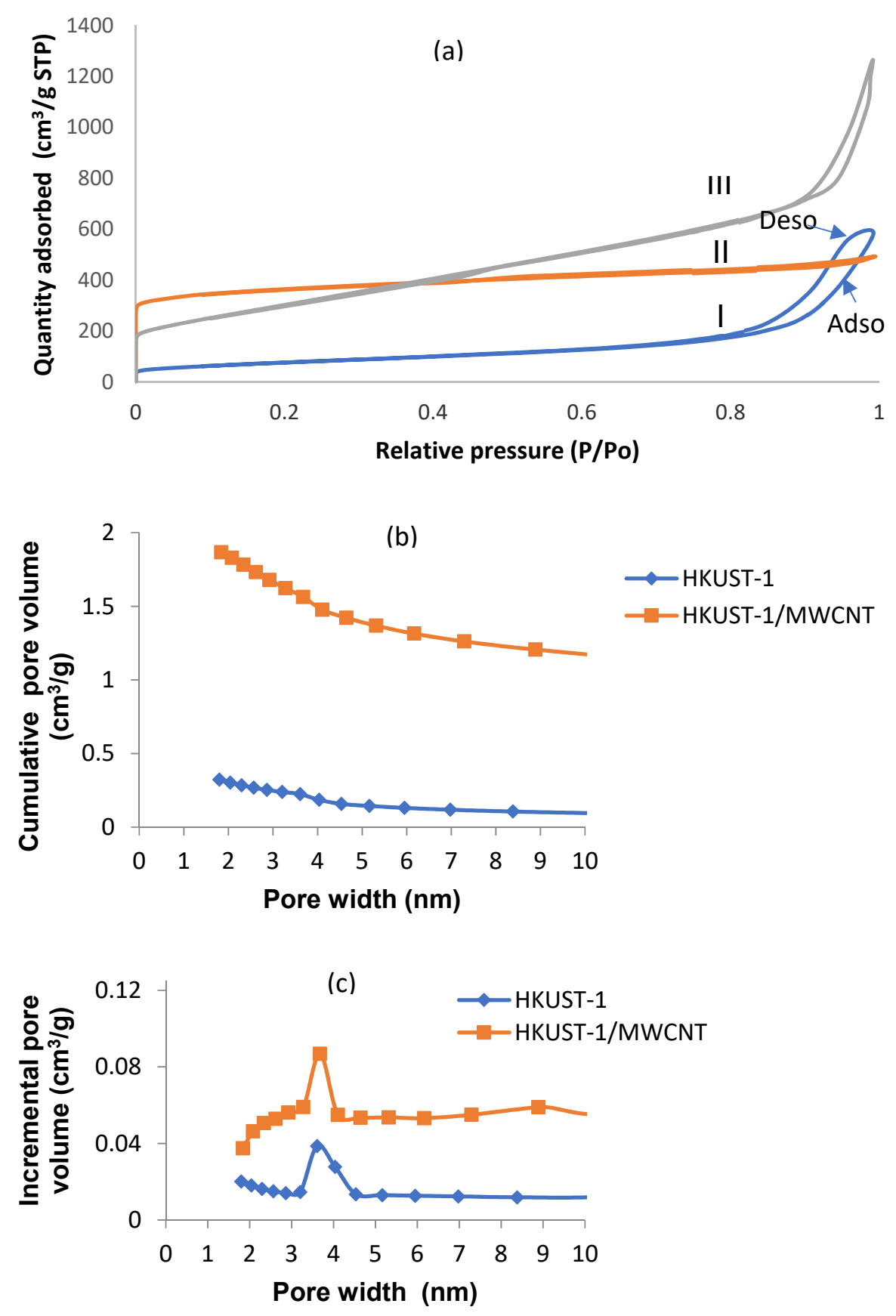

Figure 7. (a) $\mathrm{N}_{2}$ adsorption/desorption isotherms of (I) as-received MWCNTs, (II) HKUST-1, and (III) FMWCNT/HKUST-1, and BJH pore size distributions of MOF and HKUST-1 composite samples; (b) cumulative pore volume; (c) incremental pore volume.

The pore sizes of HKUST- 1 were distributed along the range of $3.2-4.5 \mathrm{~nm}$, while the pore sizes of the composites were distributed along the narrow range of $3.2-4.1 \mathrm{~nm}$. It can be observed that the addition of MWCNTs increased the virgin HKUST-1 cumulative pore volume. The large surface area and relatively high pore size and pore volume obtained in this work suggest that the material would be a good adsorbent by providing multiple channels for contaminants and increasing their immigration into the pores [14]. 


\subsection{Thermogravimetric Analysis (TGA)}

Thermogravimetric analysis of the virgin MOFs and the multiwalled carbon nanotube composites is shown in Figure 8.

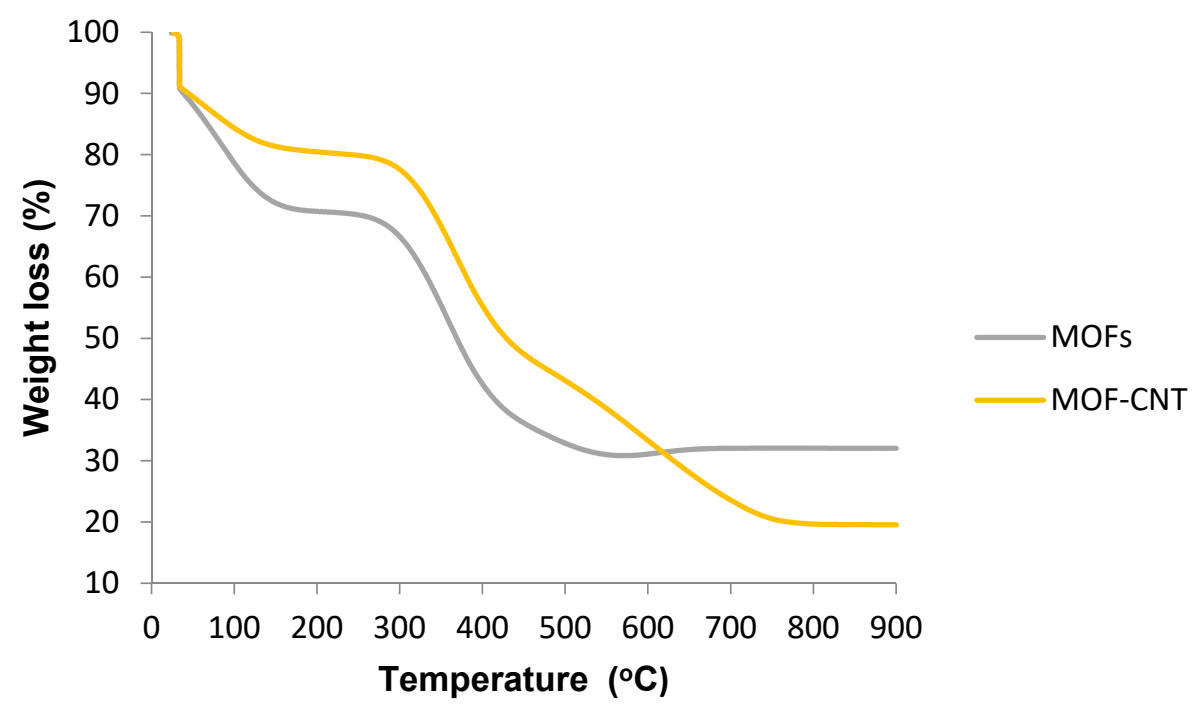

Figure 8. Thermogravimetric analysis (TGA) of HKUST-1 and FMWCNT/HKUST-1.

The thermal stability of HKUST-1 and HKUST-1/MWCNT from 35 to $900{ }^{\circ} \mathrm{C}$ revealed an initial weight loss from 35 to around $100{ }^{\circ} \mathrm{C}$, which could be attributed to the dehydration of water molecules from the surface of the samples. It can be observed that the hydrophobic characteristics of CNTs enhanced the thermal stability of virgin HKUST-1 MOF by decreasing its surface water molecules [12]. Another weight loss in HKUST-1 occurred at around $120^{\circ} \mathrm{C}$, which could have been due to the removal of solvent from the pores. The last weight loss took place at around $410{ }^{\circ} \mathrm{C}$, which could be attributed to the decomposition of the framework structure. The addition of FMWCNTs into the HKUST-1 enhanced the thermal stability of the virgin HKUST-1, as confirmed by a rise in the destruction temperature from 500 to $700{ }^{\circ} \mathrm{C}$ in HKUST-1 and FMWCNT/HKUST-1, respectively. The reason could be that the level of decomposition observed at $410^{\circ} \mathrm{C}$ in the parent HKUST-1 MOF was less than in the MWCNT/HKUST-1 composite sample.

\subsection{Adsorption Study}

The effect of $\mathrm{pH}$ has been found to be an important parameter in the adsorption of organic and inorganic wastewater treatment. This is due to its ability to influence both the adsorbent structure and the pollutant species [44,45]. Azad et al. [46] have studied the effect of $\mathrm{pH}$ on the adsorption of $\mathrm{MB}$ in an AC-HKUST-1 MOF and found that the highest adsorption occurred at $\mathrm{pH} 4$. In this work, we examined the effect of $\mathrm{pH}$ on methylene blue (MB) adsorption in FMWCNT/HKUST-1 at pH 2, 4, 6, 8 , and 10 .

In order to determine the optimal wavelength for the analysis of FMWCNT/HKUST-1, a plot of absorbance as a function of wavelength was generated. Figure 9 a shows the adsorption band maxima of the MB solution on the adsorbate at different $\mathrm{pH}$ values. Maximum absorption bands of 665, 665, 665,665 , and $664 \mathrm{~nm}$ were obtained at $\mathrm{pH} \mathrm{2,4,6,8}$, and 10, respectively. It can be noted that there was no shift in the adsorption band of aqueous MB in the FMWCNT/HKUST-1 composites. Furthermore, the effectiveness of the FMWCNT/HKUST-1 composite in the removal of MB dye was examined by evaluating its partition coefficient (PC). A partition coefficient is a solid-liquid adsorption system that has been defined as the ratio of the adsorbate per unit mass of the adsorbent to its concentration in the liquid phase at equilibrium $[47,48]$. The partition coefficient (PC) was calculated according to the report of Paulino et al. [49] and Adeyinka and Moodley [50] using different dye concentrations with 
$100 \mathrm{mg}$ of adsorbent. Partition coefficients (PCs) of $18.89,12.73$, and $10.29 \mathrm{mg} / \mathrm{g} / \mu \mathrm{M}$ were obtained for 20, 100, and 200 ppm, respectively. The performance of the FMWCNT/HKUST-1 composite could be attributed to the synergistic effect of FMWCNTs in the virgin HKUST-1 MOF in enhancing the pore structure, which provided more channels for the adsorption of MB molecules. In addition, a maximum adsorption capacity greater than $100 \mathrm{mg} / \mathrm{g}$ was obtained for $100 \mathrm{ppm}$ at $25^{\circ} \mathrm{C}$. Figure $9 \mathrm{~b}$ shows photographs of the MB solution treated with the adsorbent at $\mathrm{pH} 2$ and $\mathrm{pH} 8$.
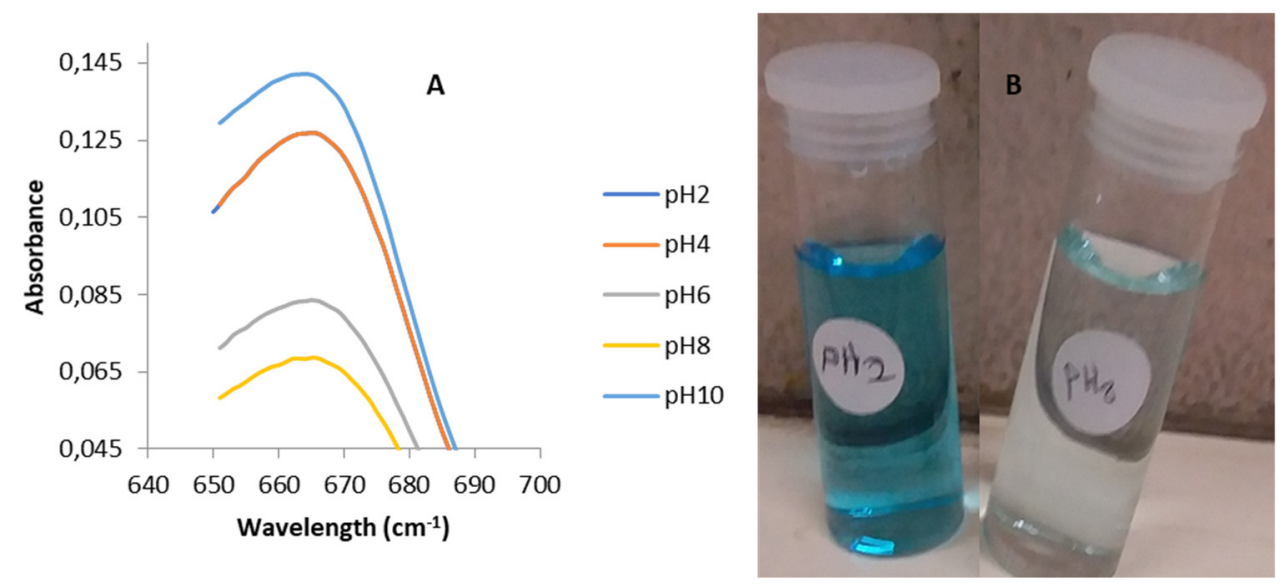

Figure 9. (A) UV-VIS spectra of methylene blue (MB) after adsorption at different $\mathrm{pH}$; (B) pictures of MB solution treated with $0.015 \mathrm{~g}$ of FMWCNT/HKUST-1 at $\mathrm{pH} 2$ and $\mathrm{pH} 8$.

The pictures reveal that MB adsorption on the FMWCNT/HKUST-1 synthesized in this work favored a basic medium, and this was evident in the residual dye solution (Figure $9 \mathrm{~b}$ ). This result is reasonably consistent with the adsorption of methylene blue on an $\mathrm{Fe}_{3} \mathrm{O}_{4} / \mathrm{Cu}_{3}(\mathrm{BTC})_{2} \mathrm{MOF}$, where the efficiency of removal of $\mathrm{MB}$ was found to be directly proportional to $\mathrm{pH}$ in the range of 2-11 [47]. On the other hand, an electrostatic interaction between the negatively charged surface of FMWCNT/HKUST-1 and the positively charged MB could have been responsible for the high adsorption [51]. In addition, the remarkable removal efficiency obtained could be attributed to the presence of a carboxylate group and a hydroxyl site in the adsorbent [14]. Furthermore, the textural properties of FWMCNT/HKUST-1 also contributed to the adsorption capacity value obtained in this work $[14,52]$.

\section{Conclusions}

This article will help scientists who want to impregnate large amounts of MWCNTs into HKUST-1 MOF to become acquainted with the simple method of synthesizing the material without damaging the nanotubes during acid treatment. The use of mild acid-treated MWCNTs coupled with the simple mixing process adopted in this work demonstrated that large-surface-area HKUST-1/MWCNT composites could be produced without the use of harsh acid treatments such as $\mathrm{H}_{2} \mathrm{SO}_{4} / \mathrm{HNO}_{3}$. The MWCNT/HKUST-1 composite produced has high surface area that is relatively equal to the virgin HKUST-1 material, even though $0.5 \mathrm{~g}$ of MWCNTs were incorporated. MWCNT addition was found to increase the pore properties without altering the structure of the parent material. The TGA plot further showed that the addition of MWCNTs enhanced the thermal decomposition temperature. The HKUST-1 hybrid composite material synthesized in this study has the potential to be used as an adsorbent in wastewater treatment. However, further investigation is required using real textile effluents to ascertain the robustness of this nanocomposite adsorbent.

Author Contributions: Conceptualization, R.S. and A.K.M.; Funding acquisition, A.K.M.; Investigation, R.S.; Methodology, R.S.; Resources, A.K.M.; Validation, A.K.M.; Writing-original draft, R.S.; Writing一review \& editing, R.S.

Funding: This research received no external funding. 
Acknowledgments: Authors are thankful for the financial support of the University of South Africa.

Conflicts of Interest: The authors declare that there are no conflicts of interest in the work reports in this paper.

\section{References}

1. Khan, N.A.; Hasan, Z.; Jhung, S.H. Adsorptive removal of hazardous materials using metal-organic frameworks (MOFs): A review. J. Hazard. Mater. 2013, 244, 444-456. [CrossRef] [PubMed]

2. Hasan, Z.; Jhung, S.H. Removal of hazardous organics from water using metal-organic frameworks (MOFs): Plausible mechanisms for selective adsorptions. J. Hazard. Mater. 2015, 283, 329-339. [CrossRef] [PubMed]

3. Zhao, X.; Zhao, H.; Dai, W.; Wei, Y.; Wang, Y.; Zhang, Y.; Gao, Z. A metal-organic framework with large 1-D channels and rich $\mathrm{OH}$ sites for high-efficiency chloramphenicol removal from water. J. Colloid Interface Sci. 2018, 526, 28-34. [CrossRef] [PubMed]

4. Li, S.; Chen, Y.; Pei, X.; Zhang, S.; Feng, X.; Zhou, J.; Wang, B. Water Purification: Adsorption over Metal-Organic Frameworks. Chin. J. Chem. 2016, 34, 175-185. [CrossRef]

5. Kumar, P.; Bansal, V.; Kim, K.-H.; Kwon, E.E. Metal-organic frameworks (MOFs) as futuristic options for wastewater treatment. J. Ind. Eng. Chem. 2018, 62, 130-145. [CrossRef]

6. Cortés-Súarez, J.; Celis-Arias, V.; Beltrán, H.I.; Tejeda-Cruz, A.; Ibarra, I.A.; Romero-Ibarra, J.E.; Loera-Serna, S. Synthesis and Characterization of an SWCNT@ HKUST-1 Composite: Enhancing the $\mathrm{CO}_{2}$ Adsorption Properties of HKUST-1. ACS Omega 2019, 4, 5275-5282. [CrossRef]

7. Ahsan, M.A.; Jabbari, V.; Islam, M.T.; Turley, R.S.; Dominguez, N.; Kim, H.; Gardea-Torresdey, J.L. Sustainable synthesis and remarkable adsorption capacity of MOF/graphene oxide and MOF/CNT based hybrid nanocomposites for the removal of Bisphenol A from water. Sci. Total Environ. 2019, 673, 306-317. [CrossRef]

8. Kang, I.J.; Khan, N.A.; Haque, E.; Jhung, S.H. Chemical and thermal stability of isotypic metal-organic frameworks: Effect of metal ions. Chem. A Eur. J. 2011, 17, 6437-6442. [CrossRef]

9. Zu, D.-D.; Lu, L.; Liu, X.-Q.; Zhang, D.-Y.; Sun, L.-B. Improving hydrothermal stability and catalytic activity of metal-organic frameworks by graphite oxide incorporation. J. Phys. Chem. C 2014, 118, 19910-19917. [CrossRef]

10. De Coste, J.B.; Peterson, G.W.; Schindler, B.J.; Killops, K.L.; Browe, M.A.; Mahle, J.J. The effect of water adsorption on the structure of the carboxylate containing metal-organic frameworks Cu-BTC, Mg-MOF-74, and UiO-66. J. Mater. Chem. A 2013, 1, 11922-11932. [CrossRef]

11. Al-Janabi, N.; Alfutimie, A.; Siperstein, F.R.; Fan, X. Underlying mechanism of the hydrothermal instability of $\mathrm{Cu}_{3}(\mathrm{BTC})_{2}$ metal-organic framework. Front. Chem. Sci. Eng. 2016, 1, 103-107. [CrossRef]

12. Zhu, L.; Meng, L.; Shi, J.; Li, J.; Zhang, X.; Feng, M. Metal-organic frameworks/carbon-based materials for environmental remediation: A state-of-the-art mini-review. J. Environ. Manag. 2019, 232, 964-977. [CrossRef]

13. Salehi, S.; Anbia, M. High $\mathrm{CO}_{2}$ adsorption capacity and $\mathrm{CO}_{2} / \mathrm{CH}_{4}$ selectivity by nanocomposites of MOF-199. Energy Fuels 2017, 31, 5376-5384. [CrossRef]

14. Jabbari, V.; Veleta, J.; Zarei-Chaleshtori, M.; Gardea-Torresdey, J.; Villagrán, D. Green synthesis of magnetic MOF@GO and MOF@ CNT hybrid nanocomposites with high adsorption capacity towards organic pollutants. Chem. Eng. J. 2016, 304, 774-783. [CrossRef]

15. Prasanth, K.; Rallapalli, P.; Raj, M.C.; Bajaj, H.; Jasra, R.V. Enhanced hydrogen sorption in single walled carbon nanotube incorporated MIL-101 composite metal-organic framework. Int. J. Hydr. Energy 2011, 36, 7594-7601. [CrossRef]

16. Cheong, V.F.; Moh, P.Y. Recent advancement in metal-organic framework: Synthesis, activation, functionalisation, and bulk production. Mater. Sci. Technol. 2018, 34, 1025-1045. [CrossRef]

17. Liang, W.; D'Alessandro, D.M. Microwave-assisted solvothermal synthesis of zirconium oxide-based metal-organic frameworks. Chem. Commun. 2013, 49, 3706-3708. [CrossRef]

18. Klinowski, J.; Paz, F.A.A.; Silva, P.; Rocha, J. Microwave-assisted synthesis of metal-organic frameworks. Dalton Trans. 2011, 40, 321-330. [CrossRef]

19. Ni, Z.; Masel, R.I. Rapid production of metal organic frameworks via microwave-assisted solvothermal synthesis. J. Am. Chem. Soc. 2006, 128, 12394-12395. [CrossRef]

20. Jung, D.-W.; Yang, D.-A.; Kim, J.; Kim, J.; Ahn, W.-S. Facile synthesis of MOF-177 by a sonochemical method using 1-methyl-2-pyrrolidinone as a solvent. Dalton Trans. 2010, 39, 2883-2887. [CrossRef] 
21. Son, W.-J.; Kim, J.; Kim, J.; Ahn, W.-S. Sonochemical synthesis of MOF-5. Chem. Commun. 2008, 47, 6336-6338. [CrossRef]

22. Campagnol, N.; Van Assche, T.; Boudewijns, T.; Denayer, J.; Binnemans, K.; De Vos, D.; Fransaer, J. High pressure, high temperature electrochemical synthesis of metal-organic frameworks: Films of MIL-100 (Fe) and HKUST-1 in different morphologies. J. Mater. Chem. A 2013, 1, 5827-5830. [CrossRef]

23. Martinez Joaristi, A.; Juan-Alcañiz, J.; Serra-Crespo, P.; Kapteijn, F.; Gascon, J. Electrochemical synthesis of some archetypical $\mathrm{Zn}^{2+}, \mathrm{Cu}^{2+}$, and $\mathrm{Al}^{3+}$ metal organic frameworks. Cryst. Growth Des. 2012, 12, 3489-3498. [CrossRef]

24. Van Assche, T.R.; Desmet, G.; Ameloot, R.; De Vos, D.E.; Terryn, H.; Denayer, J.F. Electrochemical synthesis of thin HKUST-1 layers on copper mesh. Microporous Mesoporous Mater. 2012, 158, 209-213. [CrossRef]

25. Klimakow, M.; Klobes, P.; Thünemann, A.F.; Rademann, K.; Emmerling, F. Mechanochemical synthesis of metal-Organic frameworks: A fast and facile approach toward quantitative yields and high specific surface areas. Chem. Mater. 2010, 22, 5216-5221. [CrossRef]

26. Yuan, W.; Garay, A.L.; Pichon, A.; Clowes, R.; Wood, C.D.; Cooper, A.I.; James, S.L. Study of the mechanochemical formation and resulting properties of an archetypal MOF: $\mathrm{Cu}_{3}(\mathrm{BTC})_{2}(\mathrm{BTC}=1,3$, 5-benzenetricarboxylate). CrystEngComm 2010, 12, 4063-4065. [CrossRef]

27. Fu, H.; Qin, C.; Lu, Y.; Zhang, Z.M.; Li, Y.G.; Su, Z.M.; Wang, E.B. An Ionothermal Synthetic Approach to Porous Polyoxometalate-Based Metal-Organic Frameworks. Angew. Chem. Int. Ed. 2012, 51, 7985-7989. [CrossRef]

28. Ji, W.-J.; Zhai, Q.-G.; Li, S.-N.; Jiang, Y.-C.; Hu, M.-C. The first ionothermal synthesis of a 3D ferroelectric metal-organic framework with colossal dielectric constant. Chem. Commun. 2011, 47, 3834-3836. [CrossRef]

29. Das, A.K.; Vemuri, R.S.; Kutnyakov, I.; McGrail, B.P.; Motkuri, R.K. An efficient synthesis strategy for metal-organic frameworks: Dry-gel synthesis of MOF-74 framework with high yield and improved performance. Sci. Rep. 2016, 6, 28050. [CrossRef]

30. Tan, P.; Xie, X.Y.; Liu, X.Q.; Pan, T.; Gu, C.; Chen, P.F.; Sun, L.B. Fabrication of magnetically responsive HKUST-1/Fe3O4 composites by dry gel conversion for deep desulfurization and denitrogenation. J. Hazard. Mater. 2017, 321, 344-352. [CrossRef]

31. Cacho-Bailo, F.; Catalan-Aguirre, S.; Etxeberria-Benavides, M.; Karvan, O.; Sebastian, V.; Tellez, C.; Coronas, J. Metal-organic framework membranes on the inner-side of a polymeric hollow fiber by microfluidic synthesis. J. Membr. Sci. 2015, 476, 277-285. [CrossRef]

32. Faustini, M.; Kim, J.; Jeong, G.Y.; Kim, J.Y.; Moon, H.R.; Ahn, W.S.; Kim, D.P. Microfluidic approach toward continuous and ultrafast synthesis of metal-organic framework crystals and hetero structures in confined microdroplets. J. Am. Chem. Soc. 2013, 135, 14619-14626. [CrossRef] [PubMed]

33. McKinstry, C.; Cathcart, R.J.; Cussen, E.J.; Fletcher, A.J.; Patwardhan, S.V.; Sefcik, J. Scalable continuous solvothermal synthesis of metal organic framework (MOF-5) crystals. Chem. Eng. J. 2016, 285, 718-725. [CrossRef]

34. Chen, Y.; Mu, X.; Lester, E.; Wu, T. High efficiency synthesis of HKUST-1 under mild conditions with high BET surface area and $\mathrm{CO}_{2}$ uptake capacity. Prog. Nat. Sci. Mater. Int. 2018, 28, 584-589.

35. Lin, K.-S.; Adhikari, A.K.; Ku, C.-N.; Chiang, C.-L.; Kuo, H. Synthesis and characterization of porous HKUST-1 metal organic frameworks for hydrogen storage. Int. J. Hydr. Energy 2012, 37, 13865-13871. [CrossRef]

36. Loera-Serna, S.; Solis, H.; Ortiz, E.; Martínez-Hernandéz, A.; Noreña, L. Elimination of Methylene Blue and Reactive Black 5 from Aqueous Solution Using HKUST-1. Int. J. Environ. Sci. Dev. 2017, 8, 241. [CrossRef]

37. Schlichte, K.; Kratzke, T.; Kaskel, S. Improved synthesis, thermal stability and catalytic properties of the metal-organic framework compound $\mathrm{Cu}_{3}(\mathrm{BTC})_{2}$. Microporous Mesoporous Mater. 2004, 73, 81-88. [CrossRef]

38. Ke, F.; Qiu, L.G.; Yuan, Y.P.; Peng, F.M.; Jiang, X.; Xie, A.J.; Zhu, J.F. Thiol-functionalization of metal-organic framework by a facile coordination-based postsynthetic strategy and enhanced removal of $\mathrm{Hg}^{2+}$ from water. J. Hazard. Mater. 2011, 196, 36-43. [CrossRef]

39. Wang, Q.M.; Shen, D.; Bülow, M.; Lau, M.L.; Deng, S.; Fitch, F.R.; Semanscin, J. Metallo-organic molecular sieve for gas separation and purification. Microporous Mesoporous Mater. 2002, 55, 217-230. [CrossRef]

40. Ahmed, D.S.; Haider, A.J.; Mohammad, M. Comparesion of functionalization of multi-walled carbon nanotubes treated by oil olive and nitric acid and their characterization. Energy Procedia 2013, 36, 1111-1118. [CrossRef] 
41. Jiang, H.; Feng, Y.; Chen, M.; Wang, Y. Synthesis and hydrogen-storage performance of interpenetrated MOF-5/MWCNTs hybrid composite with high mesoporosity. Int. J. Hydrog. Energy 2013, 38, 10950-10955. [CrossRef]

42. Sing, K.S. Reporting physisorption data for gas/solid systems with special reference to the determination of surface area and porosity (Recommendations 1984). Pure Appl. Chem. 1985, 57, 603-619. [CrossRef]

43. Yang, S.J.; Choi, J.Y.; Chae, H.K.; Cho, J.H.; Nahm, K.S.; Park, C.R. Preparation and enhanced hydrostability and hydrogen storage capacity of CNT@ MOF-5 hybrid composite. Chem. Mater. 2009, 21, 1893-1897. [CrossRef]

44. Yang, C.; Wu, S.; Cheng, J.; Chen, Y. Indium-based metal-organic framework/graphite oxide composite as an efficient adsorbent in the adsorption of rhodamine B from aqueous solution. J. Alloy. Compd. 2016, 687, 804-812. [CrossRef]

45. Wang, C.; Liu, X.; Chen, J.P.; Li, K. Superior removal of arsenic from water with zirconium metal-organic framework UiO-66. Sci. Rep. 2015, 5, 16613. [CrossRef] [PubMed]

46. Azad, F.N.; Ghaedi, M.; Dashtian, K.; Hajati, S.; Pezeshkpour, V. Ultrasonically assisted hydrothermal synthesis of activated carbon-HKUST-1-MOF hybrid for efficient simultaneous ultrasound-assisted removal of ternary organic dyes and antibacterial investigation: Taguchi optimization. Ultrason. Sonochem. 2016, 31, 383-393. [CrossRef]

47. Vikrant, K.; Kim, K.-H. Nanomaterials for the adsorptive treatment of Hg (II) ions from water. Chem. Eng. J. 2018, 358, 264-282. [CrossRef]

48. Liu, Y.; Hu, X. Kinetics and Thermodynamics of Efficient Phosphorus Removal by a Composite Fiber. Appl. Sci. 2019, 9, 2220. [CrossRef]

49. Paulino, A.T.; Guilherme, M.R.; Reis, A.V.; Campese, G.M.; Muniz, E.C.; Nozaki, J. Removal of methylene blue dye from an aqueous media using superabsorbent hydrogel supported on modified polysaccharide. J. Colloid Interface Sci. 2006, 301, 55-62. [CrossRef]

50. Adeyinka, G.C.; Moodley, B. Effect of aqueous concentration of humic acid on the sorption of polychlorinated biphenyls onto soil particle grain sizes. J. Soils Sediments 2019, 19, 1543-1553. [CrossRef]

51. Zhao, X.; Liu, S.; Tang, Z.; Niu, H.; Cai, Y.; Meng, W.; Giesy, J.P. Synthesis of magnetic metal-organic framework (MOF) for efficient removal of organic dyes from water. Sci. Rep. 2015, 5, 11849. [CrossRef] [PubMed]

52. Hadi, P.; Yeung, K.Y.; Barford, J.; An, K.J.; McKay, G. Significance of microporosity on the interaction of phenol with porous graphitic carbon. Chem. Eng. J. 2015, 269, 20-26. [CrossRef] 